\title{
Honoré de Balzac, I Proscritti
}

\section{Marco Stupazzoni}

\section{(2) OpenEdition}

\section{Journals}

\section{Edizione digitale}

URL: http://journals.openedition.org/studifrancesi/36382

DOI: 10.4000/studifrancesi.36382

ISSN: 2421-5856

\section{Editore}

Rosenberg \& Sellier

\section{Edizione cartacea}

Data di pubblicazione: 1 juillet 2005

Paginazione: 183

ISSN: 0039-2944

\section{Notizia bibliografica digitale}

Marco Stupazzoni, «Honoré de Balzac, I Proscritti», Studi Francesi [Online], 145 (XLIX | I) | 2005, online dal 30 novembre 2015, consultato il 20 avril 2021. URL: http://journals.openedition.org/studifrancesi/ 36382 ; DOI: https://doi.org/10.4000/studifrancesi.36382

\section{Questo documento è stato generato automaticamente il 20 avril 2021.}

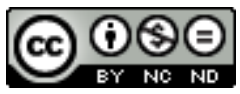

Studi Francesi è distribuita con Licenza Creative Commons Attribuzione - Non commerciale - Non opere derivate 4.0 Internazionale. 


\title{
Honoré de Balzac, I Proscritti
}

\author{
Marco Stupazzoni
}

\section{NOTIZIA}

HONORÉ DE BALZAC, I Proscritti, a cura di Daniela DE AGOSTINI, postfazione di Andrea MAZZUCCHI, Roma, Salerno Editrice, 2003 («Faville»), pp. 111.

1 Pubblicato in forma pre-originale nel $1831 \mathrm{e}$, successivamente, nel 1835, nella sua prima edizione originale, Les Proscrits rappresentano il «peristilio» di quell'edificio letterario, Le Livre mystique, nel quale Balzac fornisce la sua personale chiave di lettura del rapporto uomo-mondo-Dio, con il preciso intento di consolidare e di perfezionare $i$ fondamenti estetico-filosofici della propria arte letteraria.

2 Se considerato il relazione al vissuto del romanziere, osserva D. De Agostini nella sua ottima Introduzione, il romanzo è la testimonianza esemplare della «svolta decisiva rappresentata dalla fine del 1830 e gli inizi del 1831» (p. 9), nel momento cioè in cui, dopo la pubblicazione della Physiologie du mariage e quella delle Scènes de la vie privée, Balzac si dedicava quasi esclusivamente all'attività giornalistica. Nei Proscrits, dunque, lo scrittore «riflette la propria condizione di 'proscritto', di bandito dallo spazio letterario e costretto a perseguire con ostinazione un discorso politico solitario» (p. 14) e a riflettere sui meccanismi della propria scrittura romanzesca. Grazie ad una rinnovata interpretazione della filosofia di Swedenborg, Balzac getta le basi di una nuova visione dell'uomo e del cosmo che troverà, in Louis Lambert e in Séraphita, il suo naturale sviluppo, ma definisce, allo stesso tempo, «quello che dovrebbe essere il vero compito del romanziere-narratore capace di leggere nell'universo da lui creato i segni che lo porteranno alla scoperta del "segreto" dei sentimenti, delle azioni, del pensiero dell'uomo» (p. 17). È una sorta di "viaggio agli inferi" quello compiuto da Balzac attraverso i suoi personaggi per affrancarsi dalla condizione di esiliato della letteratura e liberare «l'energia interiore necessaria alla creazione di un'opera anzitutto visionaria» (p. 24). 
3 Da questo punto di vista, scrive A. Mazzucchi nella sua interessante e documentata postfazione (Dante "per" Balzac, pp. 89-109), risulta quanto mai illuminante la forza suggestiva esercitata su Balzac da Dante: la costruzione e l'interpretazione del personaggio dantesco come precursore delle teorie swedenborghiane e la «particolare modalità di ricezione mistica ed esoterica della Divina Commedia» consentono di comprendere meglio, nei Proscrits, «la centralità del versante visionario e cosmico della poetica balzachiana e di evitare il rischio di una troppo netta contrapposizione tra la dimensione storico-realista del romanticismo francese e quella magica, intuitiva e simbolista» (p. 104). 